\title{
Evaluation of the Microbiological Contamination of Digestive Endoscopes at the Teaching Hospital of Marrakech (Morocco)
}

\author{
Lahoucine Taoufik ${ }^{1,}$, Adil Ait Rami ${ }^{2}$, Amine El Khalfi ${ }^{1}$, Zouhour Semlani ${ }^{2,3}$, Khadija Krati ${ }^{2,3}$, \\ Nabila Soraa ${ }^{1,3}$ \\ ${ }^{1}$ Laboratory of Bacteriology Virology, ARRAZI Hospital, Marrakech, Morocco \\ ${ }^{2}$ Gastroentero-Hepatology Service, ARRAZI Hospital, Marrakech, Morocco \\ ${ }^{3}$ Faculty of Medicine and Pharmacy, Cadi Ayyad University, Marrakech, Morocco
}

Email address:

taoufiklahoucine@gmail.com (L. Taoufik)

${ }^{*}$ Corresponding author

\section{To cite this article:}

Lahoucine Taoufik, Adil Ait Rami, Amine El Khalfi, Zouhour Semlani, Khadija Krati, Nabila Soraa. Evaluation of the Microbiological Contamination of Digestive Endoscopes at the Teaching Hospital of Marrakech (Morocco). International Journal of Gastroenterology. Vol. 2, No. 1, 2018, pp. 12-17. doi: 10.11648/j.ijg.20180201.13

Received: September 23, 2018; Accepted: October 8, 2018; Published: November 5, 2018

\begin{abstract}
The purpose of this study is to evaluate the quality of endoscope disinfection at teaching Hospital of Marrakech between March 1st and June 1st, 2015. It is a prospective study of the results of microbiological tests carried out at the teaching Hospital of Marrakech between March 1st and June 1st 2015 over a period of 3 months, with digestive endoscopes. The sampling and the interpretation of the microbiological results were carried out according to the recommendations of the Technical Committee for Nosocomial Infections and Infections Linked to Health Care) (CTINILS). The results obtained showed a residual contamination of total aerobic mesophilic flora (FMAT) at the order of 4,9.103 CFU/ endoscope. 12 microorganisms were isolated and identified. Pseudomonas spp. was the most frequently isolated bacteria in these samples, (47\% of all positive samples). The rest is shared between Micrococcus spp (15\%), Staphylococcus spp (23\%) and Bacillus spp. $(10 \%)$. The corrective measures established concerning the disinfection procedure adopted in the service made it possible to eradicate the contamination at a target level (FMAT $<10 \mathrm{CFU} /$ endoscope). The respect of the basic principles of hospital hygiene and the application of rigorous cleaning and disinfection procedures are major elements in the prevention and fight against nosocomial infections.
\end{abstract}

Keywords: Contamination, Disinfection, Endoscopes

\section{Introduction}

Digestive endoscopies are diagnostic and therapeutic acts very often performed at the endoscopy unit of the hepatogastroenterology department of the University Hospital of Marrakech. The number of digestive endoscopies performed exceeds 4964 endoscopies in 2016. The complexity of the structure of endoscopes makes possible an accumulation of organic or mineral stains in certain points, more or less inaccessible to cleaning, disinfection and drying. These soils can themselves contain infectious agents and constitute anchor points for germs and substrates favorable to the multiplication of microorganisms. Insufficient frequency or quality of the disinfection procedure can lead to the formation of a biofilm [1].

Examples of patient contamination via endoscopes have been reported $[2,3]$. Thus, the infectious risk associated with endoscopy is very real and should never be neglected.

In the light of these data, the microbiological control of endoscopes is necessary and is part of the quality approach applied to endoscopy. It contributes to the validation of treatment efficacy and the identification of a potentially infectious risk situation.

The objectives of the present study are to verify the state of the digestive endoscope park in the endoscopy unit of the hepato-gastroenterology department of Mohamed VI University Hospital of Marrakech, by performing an assessment of the level 
of residual contamination of channels (linked to the presence of soil, a possible biofilm), to contribute to the evaluation of the antimicrobial action of the manual treatment procedures used in the department and to identify dysfunctions in the endoscopy unit digestive gastroenterology service at the University Hospital of Marrakech.

\section{Material and Methods}

In the absence of previous local studies, a first inventory of the whole endoscope park of the digestive endoscopy unit of the gastroenterology department was done over a period of three months.

Microbiological samples were taken after the disinfection of 25 endoscopes ( 11 colonoscopes and 14 gastroscopes):

- 22 endoscopes having undergone a complete manual disinfection procedure; just after the endoscopic act;

- 3 endoscopes, after modification of the disinfection procedure and adoption of the automated method.

\subsection{The Disinfection Protocol Evaluated}

1. In the endoscopy room: Pretreatment (external wiping / aspiration-insufflation)

2. In disinfection room:

a) Test sealing

b) $1 \mathrm{st}$ manual wash (cleaning 10min, swabbing, $1 \mathrm{st}$ rinse)

c) 2nd manual wash (cleaning 5min, abundant intermediate rinse)

d) Disinfection with Glutaraldehyde 2\% (Steranios 2\% (R):

e) Soaking time: $20 \mathrm{~min}$

f) Rinsing terminal with purge channels

3. In the stocking room: drying and storage

\subsection{Microbiological Samples}

\subsubsection{Method of Collection and Collection}

Samples were taken aseptically, immediately after the completion of the manual maintenance procedure by the Gastroenterology Resident Team responsible for the study and in the presence of microbiologists, and the specimens are labeled (date, time, site). and sent immediately to the microbiology laboratory.

\subsubsection{The sites Sampled}

- Final rinse water: volume removed $100 \mathrm{ml}$

- Disinfectant solution: volume taken $100 \mathrm{ml}$

- Endoscope:

1. Swab of the distal tip, insufflation and aspiration (after cleaning the ends with alcohol)

2. Collection of the stall solution $(0.9 \% \mathrm{NaCl}$ chloride sterile solution: $100 \mathrm{ml}$ injection into the working canal and recovery at the distal end in a sterile container)

\subsection{Processing of Levies}

\subsubsection{Seeding}

For the solutions taken (end-rinsing water, disinfection solution and stall solution), a volume of $200 \mu$ is inoculated on media enriched for quantitative culture and incubated at $37^{\circ} \mathrm{C}$ for 5 days.

For endoscopes, the swab used is cultured on enriched culture medium and incubated at $37^{\circ} \mathrm{C}$. for 5 days.

\subsubsection{Expression of Culture Results}

A total FMAT (total aerobic mesophilic flora) enumeration was performed on any positive culture and the results were expressed in colony forming unit CFU (CFU) per endoscope.

\subsubsection{Identification of Positive Cultures}

The different colonies were isolated, purified and identified according to the standard morphological, cultural and biochemical characters.

The indicator microorganisms sought were:

- Staphylococcus aureus

- Enterobacteriaceae

- Pseudomonas aeruginosa

- Other pseudomonas

- Acinetobacter sp

- Candidas sp

- Stenotrophomonas maltophilia

\subsection{Interpretation of Results}

The interpretation of the results was made according to the interpretation criteria proposed by the high council of public health in France for the microbiological control of endoscopes (Table 1).

Table 1. Interpretation of results for microbiological monitoring of endoscopes according to the CTINILS guide of March 2007 [14].

\begin{tabular}{|c|c|c|c|}
\hline Disinfection level & Target Level & alert level & action level \\
\hline $\begin{array}{l}\text { High level disinfection and rinsing with } \\
\text { sterile water }\end{array}$ & Total flora $<1 \mathrm{CFU}$ & & $\begin{array}{l}\text { Total flora }<1 \text { CFU - Total flora } \geq 1 \\
\text { CFU OR presence of } \\
\text { Microorganisms indicators } *\end{array}$ \\
\hline $\begin{array}{l}\text { Level disinfection intermediate and } \\
\text { rinsing with water bacteriologically } \\
\text { mastered } * *\end{array}$ & $\begin{array}{l}\text { Total flora }<5 \text { CFU AND absence } \\
\text { of microorganism indicator } *\end{array}$ & $\begin{array}{l}\text { Total flora 5-25 CFU AND absence } \\
\text { of microorganism indicator * }\end{array}$ & $\begin{array}{l}\text { Total flora }>25 \text { CFU OR presence of } \\
\text { Microorganisms indicators * }\end{array}$ \\
\hline $\begin{array}{l}\text { Level disinfection intermediate and } \\
\text { rinsing with water for standard care } * *\end{array}$ & $\begin{array}{l}\text { Total flora }<25 \text { CFU AND absence } \\
\text { of microorganism indicator * }\end{array}$ & $\begin{array}{l}\text { Total flora 25-100 PDU AND } \\
\text { absence of microorganism indicator * }\end{array}$ & $\begin{array}{l}\text { Total flora }>100 \text { CFU OR presence } \\
\text { of Microorganisms indicators * }\end{array}$ \\
\hline
\end{tabular}




\subsection{Statistical Analysis}

The processing and statistical analysis were done with the Excel software.

\subsection{Limitations of the Study}

Bacteriological evaluation only, No virological evaluation (HCV, HIV, HBV)

Sampling of the operator channel in monobloc

\section{Results}

Microbiological contamination of endoscopes was assessed by enumeration of FMAT and by the search for indicator microorganisms including Staphylococcus aureus, Enterobacteriaceae, Pseudomonas aeruginosa and other Pseudomonas, Stenotrophomonas maltophilia, Acinetobacter sp and Candida sp.

\subsection{Evaluation of the Level of Contamination of Digestive Endoscopes Before Disinfection}

Two samples randomly selected from a gastroscope and a colonoscope were performed after the endoscopic procedure and before disinfection.

The results of the FMAT counts were:

-Gastroscope $=2,2.105 \mathrm{CFU} /$ endoscope

-Coloscope $=3.105 \mathrm{CFU} /$ endoscope.

\subsection{Evaluation of the Level of Contamination of Collected Endoscopes $(n=88)$}

Out of 88 samples taken after manual endoscope disinfection, 40 samples showed a positive culture, ie $45 \%$ of all samples taken (figure 1).

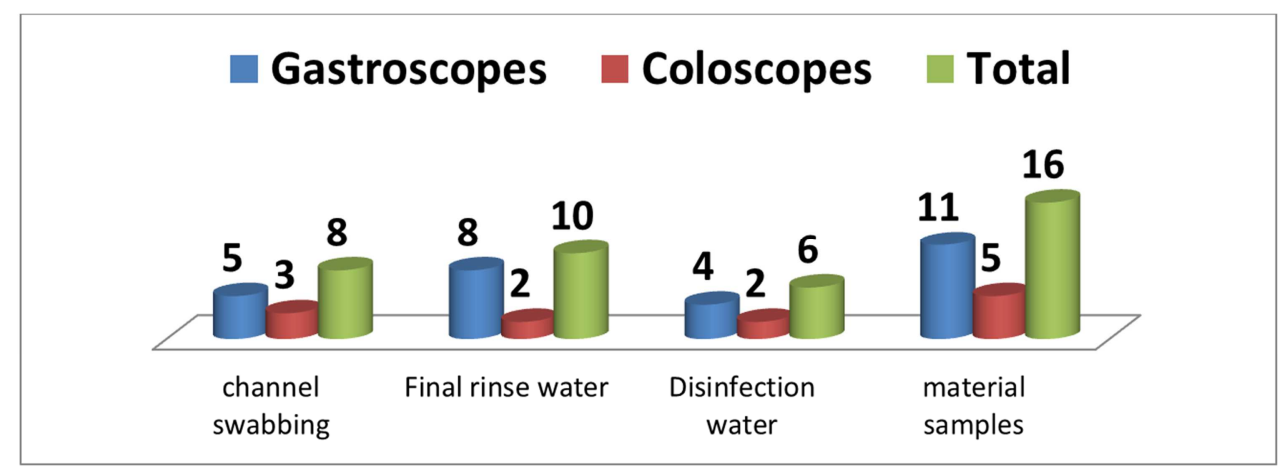

Figure 1. Overall distribution of positive samples according to the sites sampled.

The results obtained showed a residual contamination of total aerobic mesophilic flora (FMAT) in the order of $4.9 \times$ $103 \mathrm{CFU} /$ endoscope. 12 microorganisms were isolated and identified. Pseudomonas sp. was the most frequently isolated bacterium in these samples, ie $47 \%$ of all positive samples. The remainder being shared between Micrococcus sp. (Kocuriavarians) (15\%), Staphylococcus sp $(23 \%)$ and Bacillus sp. (10\%) (Table 2), (Figure 2).

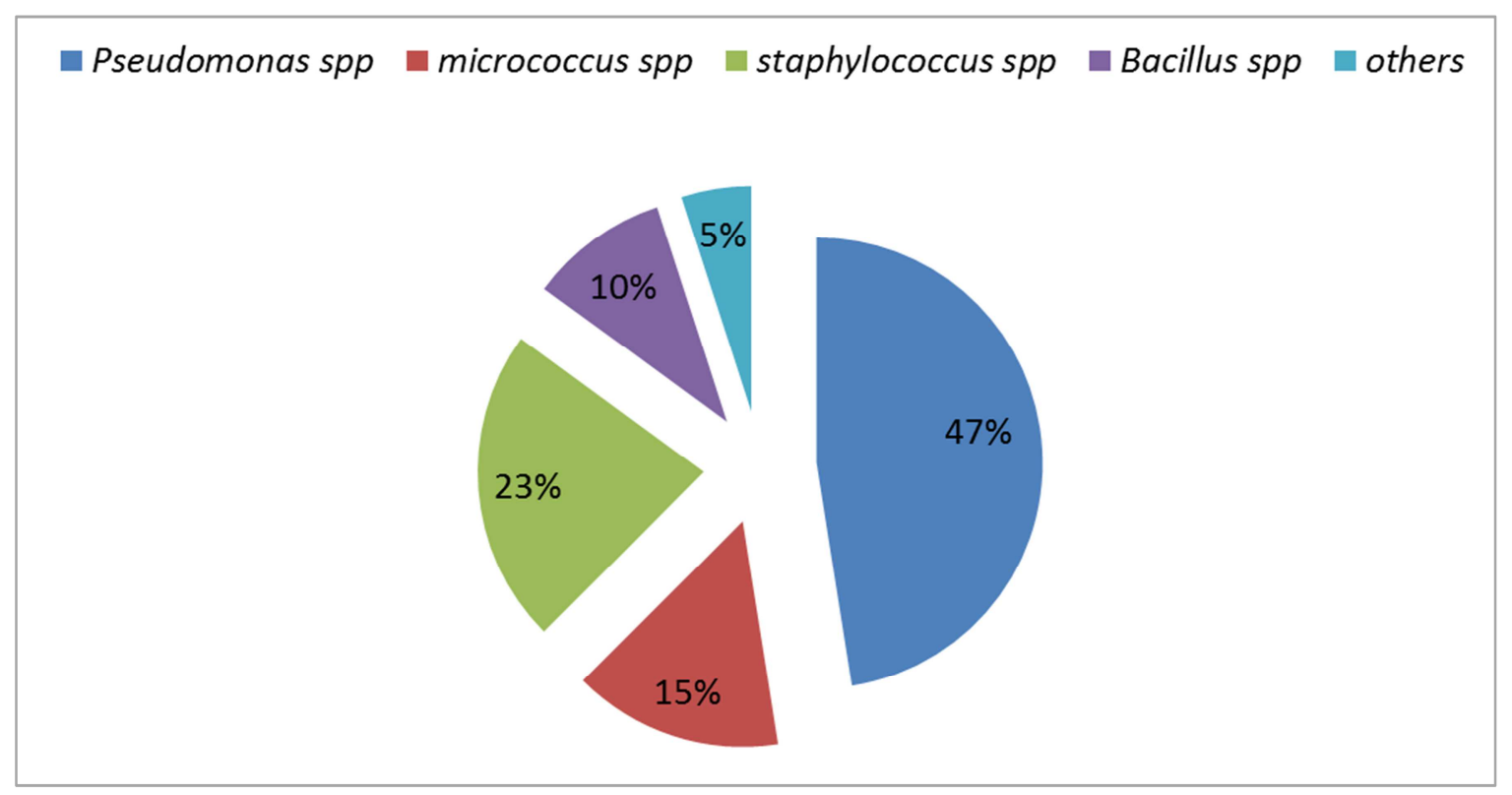

Figure 2. Distribution of isolated species from 40 positive samples after bacteriological control of digestive endoscopes ( $n=88$ sample). 
Table 2. Results of enumeration of total aerobic mesophilic flora present on digestive endoscopes according to bacterial species.

\begin{tabular}{|c|c|c|c|}
\hline & Number of Positive samples & Types of Endoscopes & Enumeration UFC / Endoscopes \\
\hline \multirow[t]{2}{*}{ Bacillus } & 4 & 2 coloscopes & $1 \times 10^{3}$ \\
\hline & & 2 gastroscopes & $1 \times 10^{3}$ \\
\hline Pseudomonas sp & 19 & 5 coloscopes & $6,2 \times 10^{3}$ \\
\hline \multirow[t]{2}{*}{ Staphylococcus } & 9 & 2 coloscopes & $1,4 \times 10^{3}$ \\
\hline & & 7 gastroscopes & $2,28 \times 10^{3}$ \\
\hline Microccocus spp & 6 & 3 coloscopes & $4 \times 10^{4}$ \\
\hline \multirow[t]{2}{*}{ Other non-fermentative BGN } & 2 & 1 coloscopes & $1 \times 10^{4}$ \\
\hline & & 1 gastroscope & $5,5 \times 10^{3}$ \\
\hline Total & 40 & 13 coloscopes $/ 27$ gastroscopes & \\
\hline
\end{tabular}

\subsection{Corrective Actions: Changing the Disinfection Procedure}

After this observation, by analyzing the causes of the dysfunction and to implement corrective actions. Thus, in coordination with the team responsible for endoscope disinfection, the adoption of the automated disinfection method has been validated to try to reduce the bacterial contamination rate of endoscopes to eliminate the risk of infection for patients.

Bacteriological control was performed at 3 endoscopes after the implementation of the automated disinfection procedure (Table 3 ). Thus, the total flora was found to be less than $10 \mathrm{CFU} /$ endoscope with the absence of bacteria at major nosocomial risk. These results correspond to the target level. This is the level of quality that aims to ensure and maintain normal operating and safety conditions in the context of a controlled environment.

Table 3. Results of microbiological controls obtained after modification of the disinfection procedure.

\begin{tabular}{lllll}
\hline & Distal Tip & Sterilization Water & Rinsing Water & samples of material \\
\hline Gastroscope & Absence & Absence & Absence & Absence \\
Coloscopes & Absence & Absence & Absence & target \\
\hline
\end{tabular}

\section{Discussion}

In terms of bacterial contamination of endoscopes, after use but before treatment, the charges found are relatively low (2.2 to $3105 \mathrm{CFU} /$ endoscope) compared to the study reported by Alfa et al. [4] who counted 106 to $107 \mathrm{CFU} /$ duodenoscope and 108 to $109 \mathrm{CFU} /$ colonoscope. These high bacterial loads impose the systematic implementation of a treatment of endoscopes after use.

Various recommendations have been published to provide a regulatory code for the cleaning and disinfection of endoscopes after each endoscopic procedure [5-6].

In this study, In this study, the protocol adopted for the microbiological control of endoscopes is that recommended by CTINILS [1]. According to the interpretation criteria recommended, the level of alertness and action are reached when the count of the total flora exceeds $25 \mathrm{CFU} /$ endoscope, or in the presence of indicator microorganisms (Staphylococcus aureus, Enterobacteriaceae, Pseudomonas aeruginosa and other Pseudomonas, Stenotrophomonas maltophilia, Acinetobacter sp., Candida sp.).

These results must imperatively trigger an immediate reaction with the end of the use of the endoscope, the analysis of the causes of the dysfunction and the implementation of corrective actions [1].

Contamination of the endoscope may indicate inadequate or faulty treatment procedures, the quality of water used during maintenance, or problems with the design of the device $[7,8]$.
These digestive endoscopes are contaminated by microorganisms at major nosocomial risk of Pseudomonas aeruginosa, coagulase-negative Staphylococcus, and Micrococcus sp.

The study conducted at the CHU de Fés (Morocco) showed the presence of other organisms such as Acinetobacter baumanni, Escherichia sp, and Candida sp [9]. This is not the case in this study.

The presence of Escherichia sp. on a fiberscope indicates a transfer of faecal contamination from a colonoscope to other types of endoscopes [10]. The transfer of contamination is done either by using the same cleaning brushes and swabs, by the manual disinfection table which is not well maintained, or by the disinfectant itself when it becomes a source of endoscope contamination when it loses its effectiveness.

The presence of coagulase-negative staphylococci and Bacillus sp. can be explained by external contamination that can not be ruled out, despite the precautions taken during sampling [11].

The drying step must be rigorous especially in the channels to avoid the progressive installation of a biofilm, which could explain the presence of Pseudomonas aeruginosa in the channels of the endoscopes studied [9].

The Algerian study has also shown the importance of compressed air drying in the reduction of nosocomial infections linked to endoscopes by yeasts specially Candida sp. [12].

This simultaneous contamination of several endoscopes evokes a dysfunction in the management of the manual disinfection of endoscopes. 
The purpose of the final rinse is to remove all traces of disinfectant from the endoscope. This step must be performed with water for standard care meeting bacteriological criteria of potability $(\leq 10 \mathrm{CFU} / 100 \mathrm{ml})$ and free from Pseudomonas aeruginosa or by bacteriologically controlled water for digestive endoscopy [13].

The presence of waterborne bacteria like Pseudomonas sp. in rinsing water requires a review of the quality and provenance of this water.

Due to the multiple ecological niches and especially of a strong pressure of antibiotic selection, P. aeruginosa is frequently found in the hospital environment.

Water points (sinks, faucets, siphons) and hospital equipment (endoscopes, nebulizers, dialysis equipment, water baths, antiseptic solutions) may be contaminated by this micro-organism [14].

In addition, the disinfectant is a key element in the disinfection procedure. It is advisable to use a glutaraldehyde detergent in $2 \%$ solution [15].

The frequency of renewal of the disinfection bath should be evaluated according to the product used and the type of endoscopy performed [16].

The results obtained after modification of the disinfection procedure in the endoscopy unit of the gastroenterology department were very satisfactory according to the data of the literature [17].

The European Society for Gynecological Endoscopy (ESGE) and the European Society of Gastroenterology and Endoscopy Nurses and Associates (ESGENA) strongly recommend the use of these disinfecting washers which have several advantages $[18,19]$ :

Procedures are standardized and validated;

traceability is ensured by the printing of a paper document which indicates all the characteristics of the different stages;

_Risks are limited for staff (closed system);

- the risks of contamination by the environment are reduced;

the work is facilitated for the staff and the saving of time is not negligible;

There is less risk of damaging the endoscopes.

However, this method requires qualified, trained staff [20] and a significant financial investment [21].

\section{Conclusion}

The sterilization methods of endoscopes are very important, their control is a critical step that can significantly reduce the number of microbiological contaminations.

This study made it possible to highlight the importance of the evaluations of the disinfection procedures, the better effectiveness of the disinfection by an automated endoscope.

\section{Conflict of Interest}

All the authors do not have any possible conflicts of interest.

\section{References}

[1] Comité technique des infections nosocomiales et des infections liées aux soins CTINILS. Eléments d'assurance qualité en hygiène relatifs au contrôle microbiologique des endospores et à la traçabilité en endoscopie. 2007. Conseil supérieur d'hygiène publique de France. Direction générale de la sante.

[2] Struelens MJ, Rost F, Deplano A, et al. Pseudomonas aeruginosa and Enterobacteriaceae bacteremia after biliary endoscopy: an outbreak investigation using DNA macrorestriction analysis. Am J Med 1993; 95 (5):489-98.

[3] Schelenz S, French G. An outbreak of multidrug-resistant Pseudomonas aeruginosa infection associated with contamination of bronchoscopes and an endoscope washerdisinfector. J. Hosp 2000; 46 (1):23-30.

[4] Alfa MJ, Degagne P, Olson N. Worst-case soiling levels for patient-used flexible endoscopes before and after cleaning. Am J Infect Control 1999; 27:392-401.

[5] Circulaire DHOS/E2/DGS/SD5C $\mathrm{n}^{\circ}$ 2003-591 du 17 décembre 2003 relative aux modalités de traitement manuel pour la désinfection des endoscopes non autoclavables dans les lieux de soins.

[6] AFSSAPS. Avis de sécurité concernant le nettoyage et la désinfection des endoscopes. DM-RECO 05/-. http:// afssaps.sante.gouv.fr/htm/alertes/filalert/ dm060708.p.

[7] Nelson DB. Infectious disease complications of GI endoscopy: part II, exogenous infections. Gastrointest Endosc 2003; 57:695-711.

[8] Weber DJ, Rutala WA. Lessons from outbreaks associated with bronchoscopy. Infect Control Hosp Epidemiol 2001; 22:403-8. MISE AU POINT/UPDATE.

[9] Oumokhtar B, El Houari H, Mustapha M, et al.Contamination microbiologique résiduelle des endoscopes digestifs Acta Endosc (2008) 5: 483-492 c Springer 2008, DOI $10.1007 / \mathrm{s} 101900800037$.

[10] Osborne S, Reynolds S, George, et al. Challenging endoscopy reprocessing guidelines. Endoscopy 2007; 39:825-30.

[11] Nelson D. Infectious disease complications of GI endoscopy. Part II: exogenous infections. Gastrointest Endosc 2003; 57:695-711.

[12] Hassaine-Lahfa I, Boucherit-Otmani Z, Sari-Belkherroubi L, et al. Retrospective study of Candida sp. contaminations of endoscopes at the University Hospital of Tlemcen (Algeria) Journal de Mycologie Médicale (2017) 670; No. of Pages 6. http://dx.doi.org/10.1016/j.mycmed.2017.01.012.

[13] Ministère chargé de la sante, DGS/DHOS, CTIN. Surveillance microbiologique de l'environnement dans les établissements de sante - Air, eaux et surfaces, 2002; 26.

[14] Cabrolier N, Lafolie J, Bertrand X. Epidemiology and risk factors of Pseudomonas aeruginosa infections. Journal des Anti-infectieux (2014) 16, 8-12.

[15] Recommandations pour le choix des produits destinés au traitement manuel des endoscopes. Acta Endosc 2000, 30 (3):416-17. 
[16] Ismaili R, Alaoui AS, Abou El Ouafa M, Zouhdi M. Hygiène et endoscopie. Revue Marocaine de Biologie Infectiologie 2004; X (1):27-36.

[17] P. Saliou, R. Garlantézec, R. Baron, et al. Microbiological investigation of endoscopes at Brest Hospital over a period from 2007 to 2009. Pathologie Biologie 59 (2011) 88-93.

[18] Beilenhoff U, et al. ESGE-ESGENA guideline: cleaning and disinfection in gastrointestinal endoscopy. Endoscopy 2008; 40:939-57.
[19] Pineau L. Laveurs-désinfecteurs d'endoscopes. Hygiènes $2002 ; 6: 431-40$.

[20] Chaudier-Delage V, Systchenko R. Maitrise du risque infectieux en endoscopie digestive. Hygiènes 2002; 6:395410.

[21] Beilenhoff U, et al. ESGE-ESGENA guideline for process validation and routine testing for endoscope reprocessing. Endoscopy 2007; 39:85-94. 